\title{
Glioblastoma, Not Otherwise Specified
}

National Cancer Institute

\section{Source}

National Cancer Institute. Glioblastoma, Not Otherwise Specified. NCI Thesaurus. Code C129295.

Glioblastoma in which there is insufficient information on the IDH genes status. 